\title{
FEASIBILITY STUDY ON ECC FATIGUE LIFE EXTENSION THROUGH SELF- HEALING
}

\author{
JISHEN QIU", PUI S. PHAN ${ }^{\dagger}$ AND EN-HUA YANG ${ }^{\dagger \dagger}$ \\ $*,+\dagger$ Nanyang Technological University \\ Singapore, Singapore \\ e-mail: jsqiu@ntu.edu.sg, phan0045@e.ntu.edu.sg, ehyang@ntu.edu.sg
}

Key words: Crack width, ECC, Fatigue life, Self-healing

\begin{abstract}
The failure of concrete infrastructures subject to repeated loading, such as bridge deck, road surface, and railway sleepers, is a result of fatigue-induced material degradation. For these infrastructures, the progressive crack propagation of concrete under fatigue loading defines the service life. The self-healing of cracks has been engaged in engineered cementitious composites (ECC), a unique group of fiber-reinforced cement-based composites that emerges to replace conventional concrete. Current study investigated the feasibility of decelerating the fatigue-induced crack propagation and extending the fatigue life of ECC by taking the advantage of self-healing. ECC prism specimens made of locally available ingredients were pre-cracked by flexural fatigue loading of different load cycles; the specimens were conditioned under wet-dry cycles for selfhealing; the self-healing efficiency was evaluated by the crack width reduction and fatigue life extension, compared to the control group without self-healing. The results indicate that self-healing can extend ECC fatigue life. The degree of crack width reduction and fatigue life extension decreased with the increasing material damage level, or the number of fatigue load cycles experienced before healing.
\end{abstract}

\section{INTRODUCTION}

Engineered cementitious composites (ECC) represent a unique group of high-performance fiber-reinforced cement-based construction materials. While ECC achieves high compressive strength comparable to Grade 3060 concrete, it also shows ultra-high tensile ductility about 1 to $5 \%$ [1], which is several hundred times that of concrete. Figure 1 illustrates the uniaxial tensile stress vs. strain of typical ECC. Unlike concrete which is failed by localized fracture, the fiber-bridging in ECC, based on micromechanics-based design, is capable of sustaining the tensile loading across the primary crack and inducing multiple cracks before failure. The fiberbridging also controls the crack widening and limits the average crack width to $100 \mu \mathrm{m}$ or below $[2,3]$.

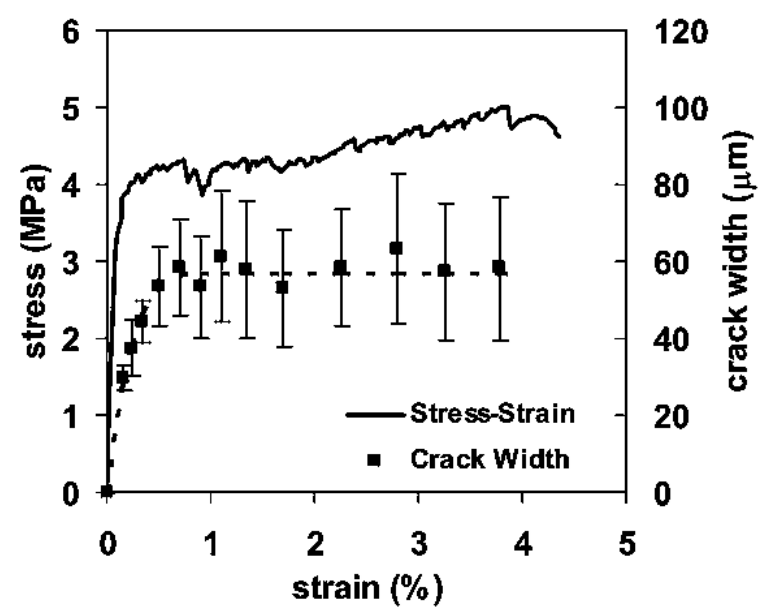

Figure 1: Typical tensile stress-strain-crack width relation of ECC. 
The ultra-high deformability and crackcontrolling capability make ECC a promising innovation in infrastructures. For instance, reinforced ECC has been used in the coupling beams in high-rise residential buildings [4]; self-consolidating ECC was used to retrofit retaining walls in deterioration [5]; most importantly in many road/bridge projects including bridge link-slab, bridge deck surface, and pavement overlay, ECC are chosen as the paving material to replace conventional concrete or asphalt [6-9]. In these applications, the high ductility of ECC can effectively mitigate the reflective cracking [10], reduce the dependence on steel reinforcement, and lead to smaller pavement thickness [11].

Studies have shown that ECC can sustain much longer fatigue life than conventional concrete [11, 12]. However, further extension on fatigue life is still highly expected, because of the relatively high cost on ECC itself and road maintenance. A good example to highlight the significance of fatigue life is the concept of electrified road [7], in which expensive charging cables will be encased in precast pavement made of rebar-free ECC, and the major repair should be delayed as much as possible.

Autogenous healing is an innovative approach to realize self-healing in deteriorated cementitious materials. Being different from other approaches like mineral precipitation by bacteria or encapsulated healing chemical, autogenous healing requires no special healing agents in the mix design [13]. Specifically, in the presence of water, $\mathrm{Ca}^{2+}$ ions in the cement hydrates are leached out and combined with dissolved $\mathrm{CO}_{2}$ forming $\mathrm{CaCO}_{3}$. $\mathrm{ECC}$ is capable of efficient autogenous healing, because relatively high alkalinity can be maintained in the fine cracks, which promotes $\mathrm{CaCO}_{3}$ precipitation. Yang et al. [14, 15] found significant tensile strength and stiffness recovery in cracked ECC after autogenous healing. The degree of mechanical recovery depends on the crack width: complete recovery was noticed if the crack width was limited to $50 \mu \mathrm{m}$ or below; no recovery if the crack width was above $150 \mu \mathrm{m}$.
The mechanical recovery indicates that it is plausible to regain the fatigue resistance of ECC through autogenous healing techniques. However, no experimental work has been conducted to confirm such potential. In current study, the feasibility of extending ECC fatigue life through autogenous healing is studied.

\section{EXPERIMENTAL PROGRAMS}

\subsection{Specimen preparation}

Flexural fatigue tests were conducted to ECC prism $\left(280 \times 70 \times 50 \mathrm{~mm}^{3}\right)$ that were precracked and healed. The flexural fatigue performance of healed ECC was compared with that of control group.

Table 1: Elementary composition of GGBS

\begin{tabular}{lrrrrc}
\hline $\mathrm{CaO}$ & $\mathrm{SiO}_{2}$ & $\mathrm{Al}_{2} \mathrm{O}_{3}$ & $\mathrm{MgO}$ & $\mathrm{SO}_{3}$ & Others \\
\hline $39.4 \%$ & $31.2 \%$ & $13.4 \%$ & $9.3 \%$ & $4.3 \%$ & $2.4 \%$ \\
\hline
\end{tabular}

Type I Portland cement (CEM I 52.5N), ground granulated blast-furnace slag (GGBS), fine river sands, fine rubber powders, tap water, superplasticizer were used as ingredients to prepare the matrix of ECC prisms. Cement and GGBS are used as binder materials. The chemical composition of GGBS was given in Table 1. River sand and rubber powders were used as fine aggregates. The maximum particle size of river sand and rubber powders were limited to $0.6 \mathrm{~mm}$ and $0.2 \mathrm{~mm}$ respectively. Short PVA fibers, as the matrix reinforcement, were added to the ECC specimens only. The length and diameter of PVA fibers were controlled at $12 \mathrm{~mm}$ and 39 $\mu \mathrm{m}$; the fiber strength was $1600 \mathrm{MPa}$. Mix proportions of ECC prisms are given in Table 2. In ECC, rubber powders were intentionally introduced to reduce the matrix toughness for multiple cracking.

A three-gear planetary mixer was used for specimen preparation. At the beginning all solid ingredients except for fibers were dry mixed for two minutes. Water and superplasticizer were slowly added into the mixture at low mixing speed within one minute, followed by medium mixing speed for another two minutes to achieve required rheology. For ECC prisms, short PVA fibers were then slowly added into the mixture at low 
mixing speed within one minute, followed by medium mixing speed for three minutes for fiber dispersion. The fresh mixtures hardened after one day and demolded. All the specimens were cured in laboratory condition (air-curing, $20^{\circ} \mathrm{C}$ ) for at least 28 days before any testing.

Table 2: Mix proportions design

\begin{tabular}{ll}
\hline Ingredients & ECC prism \\
\hline Cement & 1.00 \\
\hline GGBS & 0.43 \\
\hline River sand & 0.21 \\
\hline Rubber powder & 0.14 \\
\hline Superplasticizer & 0.005 \\
\hline PVA fiber & 0.032 \\
\hline Density $\left(\mathrm{kg} / \mathrm{m}^{3}\right)$ & 1920 \\
\hline
\end{tabular}

\subsection{Flexural fatigue test on self-healed ECC}

Four-point flexural fatigue test was used to evaluate the fatigue resistance of ECC. To evaluate the effect of self-healing on fatigue life extension, predetermined cycles of fatigue preloading was introduced to groups 3 to 5 followed by 14 wet-dry conditioning cycles to engage healing and fatigue reloading until the end life. Table 3 shows the testing program. A flexural load level of 0.80 modulus of rupture (MOR) was used for all fatigue tests. Two control groups, i.e. Group 1 and 2 were included. For Group 1, fatigue loading was directly applied to the specimens without preloading and wet-dry conditioning so that the fatigue life of the original specimens was determined. For Group 2, the specimens were conditioned for 14 wet-dry cycles followed by fatigue loading until failure. This was to exclude the effect of further hydration of ECC subject to the wet-dry conditioning, which may also contributes to change of fatigue life. For Groups 3-5, the specimens were preloaded under fatigue of $387,1,700$, and 5,100 cycles respectively, followed by 14 wet-dry conditioning cycles to engage healing, after which the healed samples were reloaded under fatigue to failure. For each group, at least five specimens were tested. The details of fatigue loading program and self-healing conditioning are given in Table 3 .

Table 3: Testing program of flexural fatigue and selfhealing

\begin{tabular}{llll}
\hline Grp. Step 1 & Step 2 & Step 3 \\
\hline 1 & & $\begin{array}{l}\text { Fatigue } \\
\text { loading }\end{array}$ \\
\hline 2 & $\begin{array}{l}\text { 14 wet-dry } \\
\text { conditioning }\end{array}$ & $\begin{array}{l}\text { Fatigue } \\
\text { loading }\end{array}$ \\
\hline 4 & $\begin{array}{l}\text { Fatigue preloading } \\
\text { (1700 cycles) }\end{array}$ & $\begin{array}{l}\text { 14 wet-dry } \\
\text { conditioning }\end{array}$ & $\begin{array}{l}\text { Fatigue } \\
\text { reloading }\end{array}$ \\
\hline 5 & $\begin{array}{l}\text { Fatigue preloading } \\
\text { (5100 cycles) }\end{array}$ & $\begin{array}{l}\text { 14 wet-dry } \\
\text { conditioning } \\
\text { conditioning }\end{array}$ & $\begin{array}{l}\text { Fatigue } \\
\text { reloading }\end{array}$ \\
\hline
\end{tabular}

All the flexural tests in this section were conducted with MTS Landmark servohydraulic testing machine. The MOR of ECC was determined by the displacementcontrolled $(0.2 \mathrm{~mm} / \mathrm{min})$ monotonic four-point flexural test beforehand. For current mix design, the MOR was measured as $7.33 \pm 0.76$ $\mathrm{MPa}$. The fatigue tests were controlled by loading force: loading frequency equaled to 5 $\mathrm{Hz}$ with a maximum load of $0.80 \mathrm{MOR}$ and a minimum load of $0.20 \mathrm{MOR}$. A relatively high load level was chosen to shorten the testing duration. The real-time deflection during the fatigue tests was also recorded. For the selfhealing sessions, every cycle of wet-dry conditioning consisted of submerging the specimens in water $\left(20^{\circ} \mathrm{C}\right)$ for one day, followed by exposing the specimens in air $\left(20^{\circ} \mathrm{C}\right)$ for another day, which was suggested by [14].

In addition to mechanical performance, crack width reduction was also measured to evaluate the degree of healing. Images of cracks before and after conditioning were taken at magnification with a Nikon DS-Fi2 high resolution camera. The crack width was measured at high-magnification image to monitor changes of crack width. Crack number on each specimen was also recorded after every fatigue loading session. 


\section{RESULTS AND DISCUSSION}

\subsection{Effect of self-healing on flexural fatigue}

Figure 2 illustrates the flexural fatigue life distribution of ECC specimens from Group 1 to 5. It can be seen that the fatigue life of ECC with different loading and conditioning history significantly varied. The extension of fatigue life from Group 1 (6863 cycles) to Group 2 (25272 cycles) can be attributed to the continued hydration during the water curing period, which led to higher matrix strength. The comparison of healed groups, i.e. Group 3-5, to Group 2, shows the feasibility of extending ECC fatigue life through selfhealing. Group 3, the specimens of which were conditioned after 387 fatigue cycles, sustained 49649 cycles in average, almost doubling the fatigue life of Group 2. However, fatigue life of ECC was gradually shortened with increase of fatigue damage level, as shown by Group 4 (35004 cycles) and Group 5 (12138 cycles), the specimens of which were conditioned after 1700 and 5100 fatigue cycles respectively.

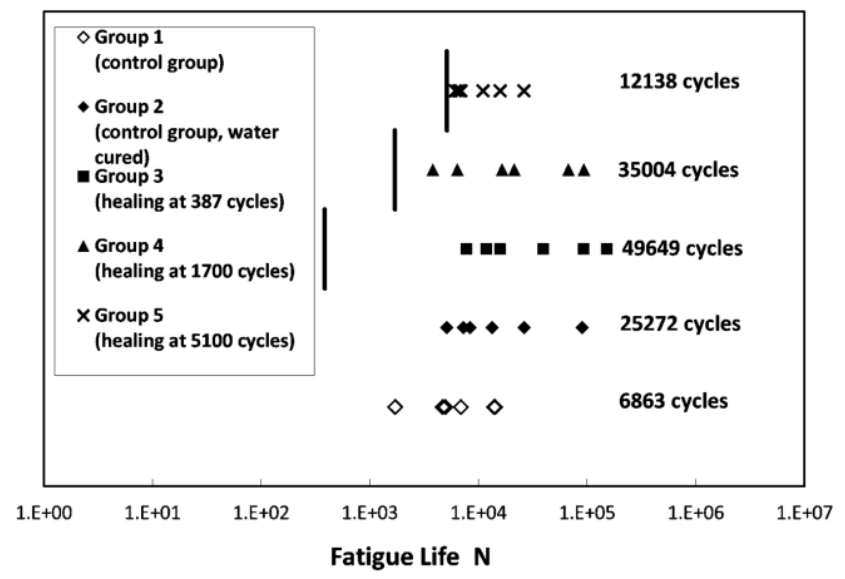

Figure 2: Fatigue life of ECC specimens from Group 1 to 5 , each vertical bar represent 14 wet-dry cycles of conditioning for healing

Fatigue is a process of material deterioration. In the load-controlled flexural fatigue test, such deterioration can be reflected by the progressive deflection. Figure 3 shows the typical relation between deflection and load cycles. The deflection increased dramatically at the beginning due to the dynamic effect during force ramping; then it gradually entered into a relatively stable stage, where the curve shows a linear trend; approaching specimen failure, the deflection increased very fast until the specimen rupture. Instead of the dramatic deflection enhancement at the beginning or near the end of the test, the stable linear stage better represent the fatigue resistance of the material. As a result, the deflection increasing rate, i.e. the slope of curves, was compared in Figure 4.

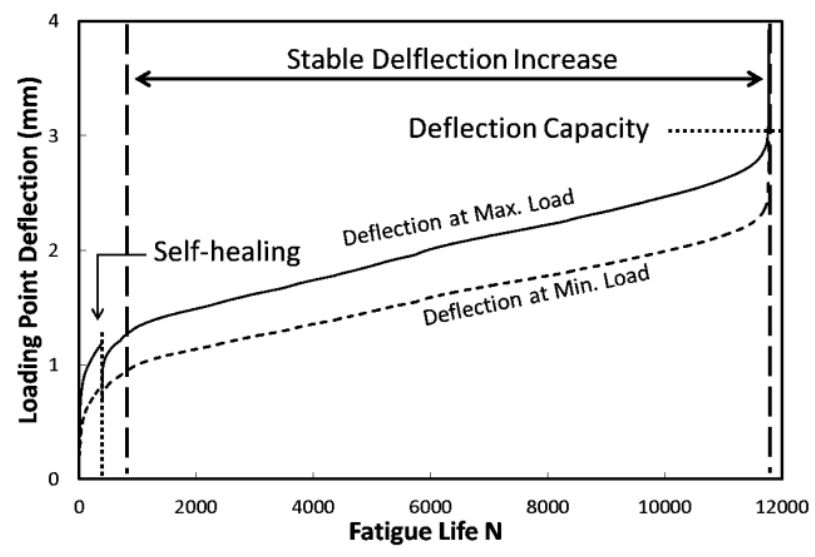

Figure 3: Typical loading point deflection increase with faitgue load cycles

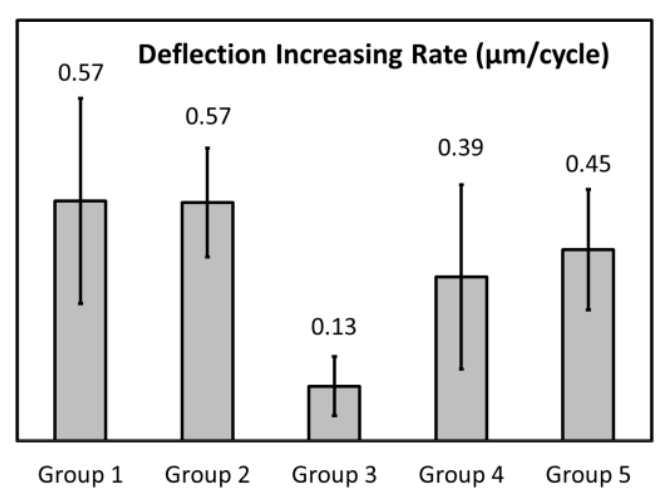

Figure 4: Comparison of deflection increasing rate during fatigue test

In Figure 4, it can be seen that deflection increasing rate of the self-healed groups (Group 3-5) was remarkably reduced from the control groups (Group 1 and 2). It indicates that self-healing effectively decelerated the material deterioration. Among the healed groups, the slowest deflection increase was observed in Group $3(0.13 \mu \mathrm{m} /$ cycle $)$, which was healed after 387 load cycles only; while faster deflection increase was observed in Group 4 and $5(0.39 \mu \mathrm{m} /$ cycle and 0.45 
$\mu \mathrm{m} /$ cycle respectively), which had experienced 1700 and 5100 load cycles before healing started.

Figure 5 illustrates the normalized flexural stiffness of healed groups (Group 3-5) through the fatigue tests. The flexural stiffness is calculated as the ratio of fatigue amplitude $\left(\mathrm{P}_{\max }-\mathrm{P}_{\min }\right)$ over the displacement amplitude. The normalized stiffness is calculated as the ratio of stiffness in current cycle over that in the first cycle. It can be seen that the flexural stiffness kept decreasing with increasing number of load cycle but greatly recovered when the healing conditioning was applied. The degree of such mechanical recovery highly depends on the damage level, or the fatigue load cycles experienced. Lower damage level leads to higher degree of healing-induced recovery.

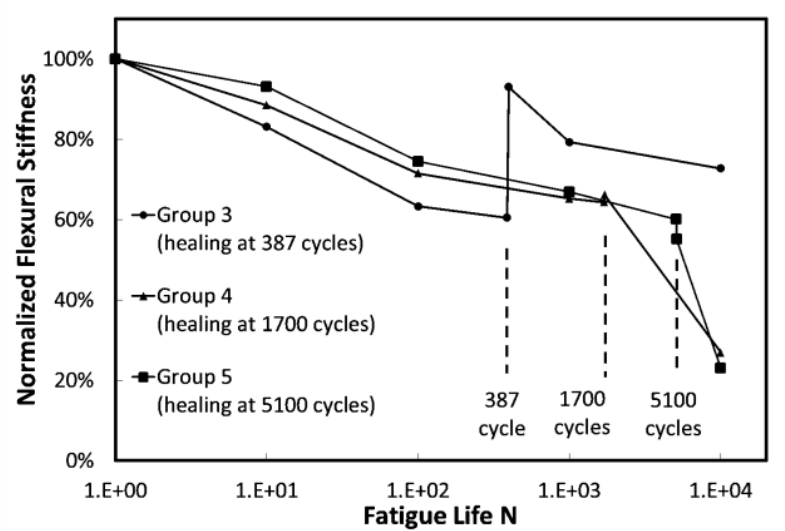

Figure 5: Normalized flexural stiffness vs. load cycles

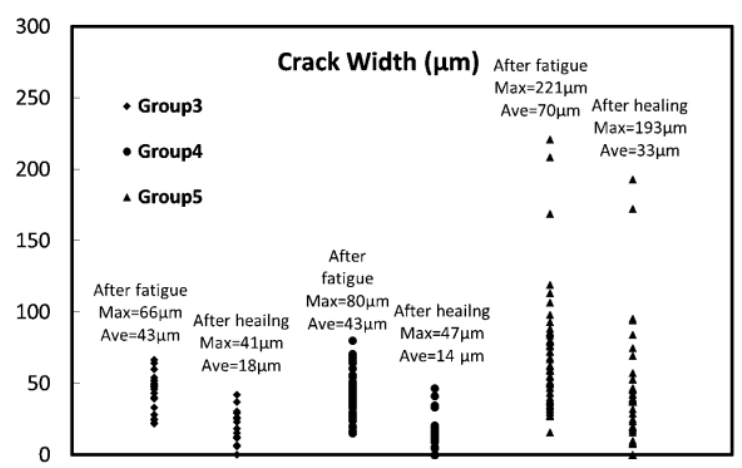

Figure 6: Crack width in ECC specimen before and after self-healing

Figure 6 illustrated the ECC crack width before and after healing conditioning. The crack width increased with the fatigue load cycles; self-healing effectively reduced the crack width, some fine cracks were even completely sealed; the crack width reduction; the degree of crack width reduction of Group 5 was greater than that of Group 3 and 4.

\subsection{Discussion}

In Figure 2, it is noticed that the Groups 3 and 4 , after the fatigue pre-cracking and healing conditioning, sustained averagely $49,262 \quad(=49,649-387)$ fatigue cycles and $33,304 \quad(=35,004-1,700)$ fatigue cycles respectively, which are longer fatigue life than the water-cured control Group 2. In Figure 4, it is also noticed that the deflection increasing rate of Groups 3 and 4, after healing conditioning, are smaller than that of Group 2. It is observed that in Groups 3-5 some specimens eventually ruptured at a new crack generated in the second fatigue test, rather than an old crack generated in the first fatigue test, as summarized in Table 5. These observations imply that the self-healing of ECC is not only a process of fiber-bridging recovery towards its original status, but also a process of fiberbridging improvement beyond the original status. It is known that the flexural strength of ECC is dependent on its fiber-bridging across the crack, which subsequently depends on the fiber-matrix interfacial bond. It may be attributed to that the healing products create stronger fiber-matrix interfacial bond between fiber and matrix during the healing conditioning. Further material characterization must be conducted to understand the microstructural change at the fiber-matrix interface.

Table 4: Probability of specimen rupture at a new crack generated after self-healing

\begin{tabular}{llll}
\hline Group No. & 3 & 4 & 5 \\
\hline $\begin{array}{l}\text { Fatigue preloading } \\
\text { cycles }\end{array}$ & 387 & 1700 & 5100 \\
\hline $\begin{array}{l}\text { Number of specimens } \\
\text { Number of specimen }\end{array}$ & 6 & 6 & 7 \\
\hline $\begin{array}{l}\text { ruptured at a new } \\
\text { crack location }\end{array}$ & 5 & 2 & 1 \\
\hline Percentage & $83 \%$ & $33 \%$ & $14 \%$ \\
\hline
\end{tabular}




\section{CONCLUSIONS}

The feasibility of extending fatigue life of ECC through self-healing is studied. Flexural fatigue test was conducted to ECC prisms that underwent self-healing conditioning; the fatigue life was compared with control groups. Following conclusions are drawn based on the experimental results: Self-healing can effectively reduce the crack width, recover flexural stiffness, and extend the flexural fatigue life of ECC. The degree of mechanical enhancement depends on the fatigue damage level when engaging self-healing. Early engagement of healing is necessary for fatigue resistance recovery of ECC as the fatigue crack width and fiber-bridging deterioration increases with load cycles.

\section{REFERENCES}

[1] V.C. Li, On engineered cementitious composites (ECC), Journal of advanced concrete technology, 1 (2003) 215-230.

[2] V.C. Li, S. Wang, C. Wu, Tensile strainhardening behavior of polyvinyl alcohol engineered cementitious composite (PVAECC), ACI Materials Journal, 98 (2001).

[3] E.-H. Yang, Y. Yang, V.C. Li, Use of high volumes of fly ash to improve ECC mechanical properties and material greenness, ACI Materials Journal, 104 (2007).

[4] M. Maruta, T. Kanda, S. Nagai, Y. Yamamoto, New high-rise RC structure using pre-cast ECC coupling beam, Concrete Journal, 43 (2005) 18-26.

[5] Y.Y. Kim, G. Fischer, Y.M. Lim, V.C. Li, Mechanical performance of sprayed engineered cementitious composite using wet-mix shotcreting process for repair applications, ACI Materials Journal, 101 (2004).

[6] V.C. Li, M.D. Lepech, M. Li, Field demonstration of durable link slabs for jointless bridge decks based on strainhardening cementitious composites, 2005.

[7] N. NguyenDinh, E.-H. Yang, B. Lecher, Precast Electrified Roadway Pavement Systems Using Engineered Cementitious Composites, Proceedings of the 12th
International Symposium on Concrete Roads, Prague Czech Republic, 2014.

[8] K. Rokugo, T. Kanda, H. Yokota, N. Sakata, Applications and recommendations of high performance fiber reinforced cement composites with multiple fine cracking (HPFRCC) in Japan, Materials and structures, 42 (2009) 1197-1208.

[9] S. Qian, V. Li, H. Zhang, G. Keoleian, Life cycle analysis of pavement overlays made with Engineered Cementitious Composites, Cement and Concrete Composites, (2012).

[10] J. Zhang, V.C. Li, Monotonic and fatigue performance in bending of fiberreinforced engineered cementitious composite in overlay system, Cement and Concrete Research, 32 (2002) 415-423.

[11] S. Qian, Influence of concrete material ductility on the behavior of high stress concentration zones, ProQuest2007.

[12] P. Suthiwarapirak, T. Matsumoto, T. Kanda, Multiple cracking and fiber bridging characteristics of engineered cementitious composites under fatigue flexure, Journal of materials in civil engineering, 16 (2004) 433-443.

[13] V.C. Li, E. Herbert, Robust self-healing concrete for sustainable infrastructure, Journal of Advanced Concrete Technology, 10 (2012) 207-218.

[14] Y. Yang, M.D. Lepech, E.-H. Yang, V.C. $\mathrm{Li}$, Autogenous healing of engineered cementitious composites under wet-dry cycles, Cement and Concrete Research, 39 (2009) 382-390.

[15] Y. Yang, E.-H. Yang, V.C. Li, Autogenous healing of engineered cementitious composites at early age, Cement and concrete research, 41 (2011) 176-183.

[16] C. Redon, V.C. Li, C. Wu, H. Hoshiro, T. Saito, A. Ogawa, Measuring and modifying interface properties of PVA fibers in ECC matrix, Journal of Materials in Civil Engineering, 13 (2001) 399-406. 